DOC.20040901.0004

QA:QA

ANL-EBS-PA-000009 REV 01

September 2004

BECHTEL SAIC conpanü

\title{
Sampling of Stochastic Input Parameters for Rockfall Calculations and for Structural Response Calculations Under Vibratory Ground Motion
}

Prepared for:

U.S. Department of Energy

Office of Civilian Radioactive Waste Management

Office of Repository Development

1551 Hillshire Drive

Las Vegas, Nevada 89134-6321

Prepared by:

Bechtel SAIC Company, LLC

1180 Town Center Drive

Las Vegas, Nevada 89144

Under Contract Number

DE-AC28-01RW12101 


\section{DISCLAIMER}

This report was prepared as an account of work sponsored by an agency of the United States Government. Neither the United States Government nor any agency thereof, nor any of their employees, nor any of their contractors, subcontractors or their employees, makes any warranty, express or implied, or assumes any legal liability or responsibility for the accuracy, completeness, or any third party's use or the results of such use of any information, apparatus, product, or process disclosed, or represents that its use would not infringe privately owned rights. Reference herein to any specific commercial product, process, or service by trade name, trademark, manufacturer, or otherwise, does not necessarily constitute or imply its endorsement, recommendation, or favoring by the United States Government or any agency thereof or its contractors or subcontractors. The views and opinions of authors expressed herein do not necessarily state or reflect those of the United States Government or any agency thereof. 
Sampling of Stochastic Input Parameters for Rockfall Calculations and for Structural Response Calculations Under Vibratory Ground Motion

ANL-EBS-PA-000009 REV 01

September 2004 


\section{OCRWM}

\section{Scientific Analysis Signature Page/ Change History}

Page iii

1. Total Pages: 42

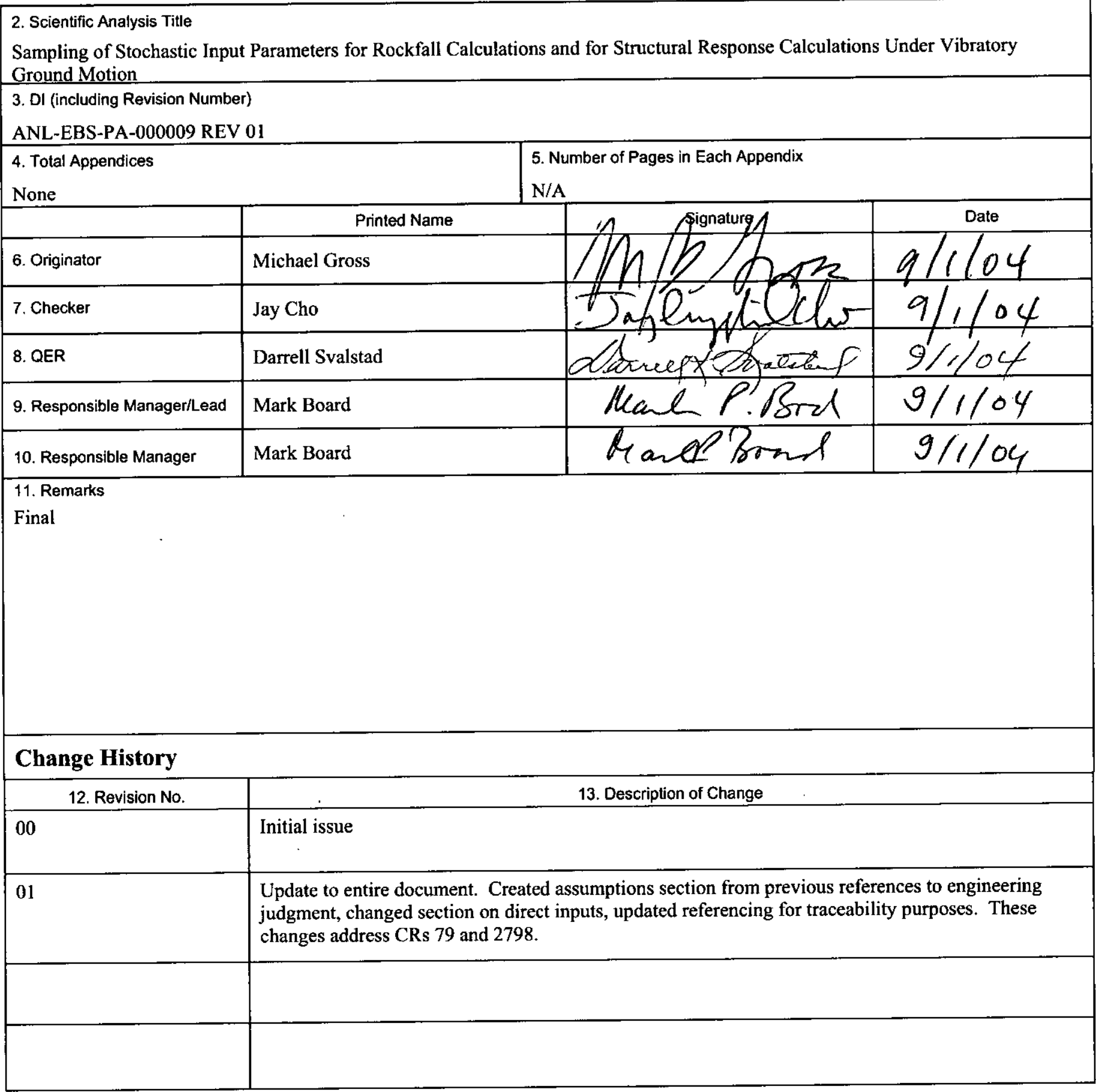




\section{CONTENTS}

Page

ACRONYMS AND ABBREVIATIONS ix

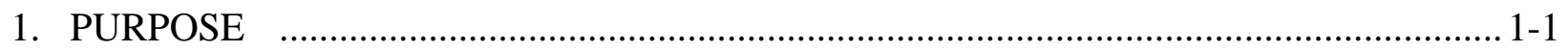

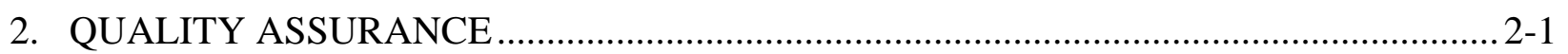

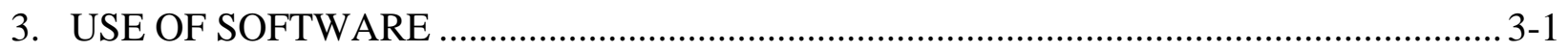

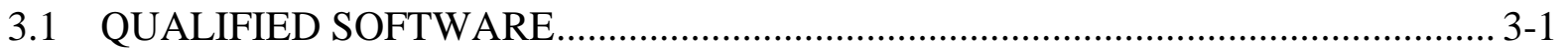

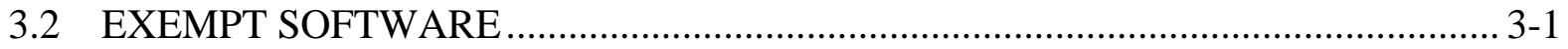

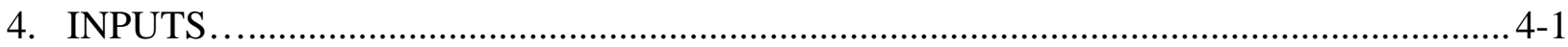

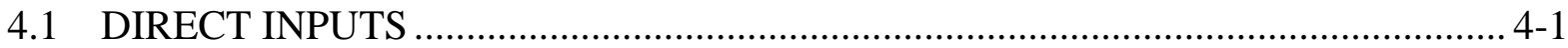

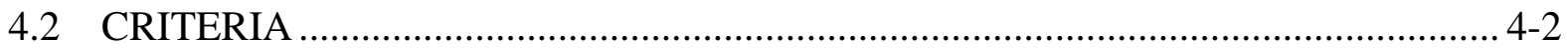

4.3 CODES, STANDARDS, AND REGULATIONS ..................................................... 4-3

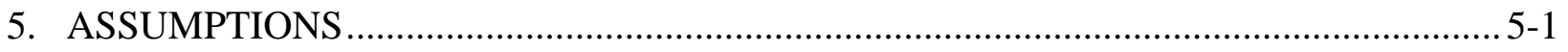

5.1 MAJOR UNCERTAIN PARAMETERS FOR ROCKFALL MODELING ................ 5-1

5.2 NUMBER OF REALIZATIONS FOR ROCKFALL ANALYSES .............................. 5-1

5.3 MAJOR UNCERTAIN PARAMETERS FOR VIBRATORY STRUCTURAL ANALYSIS ...................................................................................................... 5-2

5.4 FRICTION COEFFICIENTS AS INPUT TO VIBRATORY STRUCTURAL ANALYSIS .....................................................................................................

5.5 USE OF UNIFORM DISTRIBUTION FOR FRICTION COEFFICIENTS FOR VIBRATORY STRUCTURAL ANALYSIS ........................................................ 5-4

6. SCIENTIFIC ANALYSIS DISCUSSION...................................................................... 6-1

6.1 INITIAL SAMPLING FOR ROCKFALL CALCULATIONS IN THE

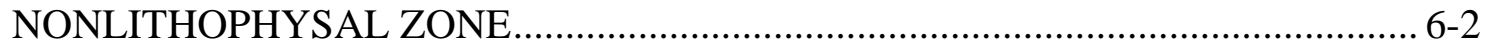

6.1.1 Identification of Uncertain Parameters ......................................................... 6-2

6.1.2 Computational Results ............................................................................... 6-2

6.2 SECOND SAMPLING FOR ROCKFALL CALCULATIONS IN THE NONLITHOPHYSAL ZONE........................................................................ 6-4

6.2.1 Identification of Uncertain Parameters ....................................................... 6-4

6.2.2 Computational Results ......................................................................... 6-4

6.3 SAMPLING FOR ROCKFALL CALCULATIONS IN THE LITHOPHYSAL

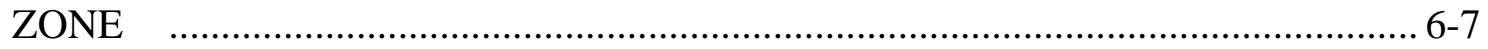

6.3.1 Identification of Uncertain Parameters ........................................................ 6-7

6.3.2 Computational Results ........................................................................ 6-8

6.4 SAMPLING FOR STRUCTURAL RESPONSE CALCULATIONS ...................... 6-10

6.4.1 Identification of Uncertain Parameters .................................................... 6-10

6.4.2 Computational Results ........................................................................... 6-10

6.5 DISCUSSION OF YUCCA MOUNTAIN REVIEW PLAN ACCEPTANCE

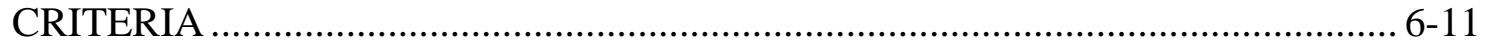




\section{CONTENTS (Continued)}

Page

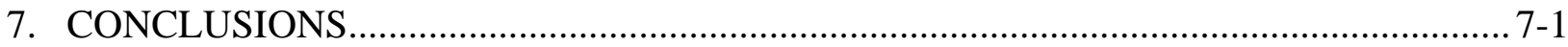

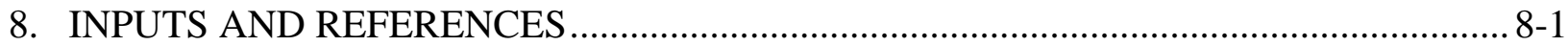

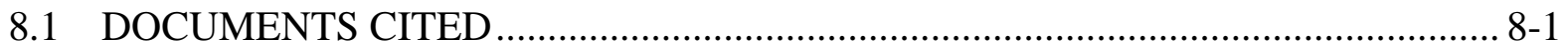

8.2 CODES, STANDARDS, REGULATIONS, AND PROCEDURES ............................ 8-2

8.3 OUTPUT DATA, LISTED BY DATA TRACKING NUMBER ……........................ 8-2

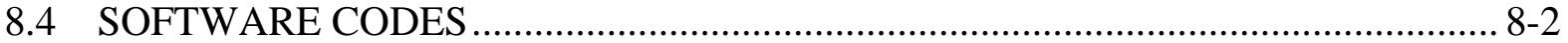




\section{TABLES}

Page

6-1. First Sampling of Input Values for Rockfall Calculations in the Nonlithophysal Zone as a Result of the GoldSim Calculations

6-2. Second Sampling of Input Values for Rockfall Calculations in the Nonlithophysal Zone as a Result of the GoldSim Calculations

6-3. Input Values for Rockfall Calculations in the Lithophysal Zone as a Result of the GoldSim Calculations

6-4. Input Values for Structural Response Calculations as a Result of the GoldSim Calculations. 
Sampling of Stochastic Input Parameters for Rockfall Calculations and for Structural Response Calculations Under Vibratory Ground Motion

\section{INTENTIONALLY LEFT BLANK}




\section{ACRONYMS AND ABBREVIATIONS}

BSC Bechtel-SAIC Company, LLC

CFR Code of Federal Regulations

DTN Data Tracking Number

EBS Engineered Barrier System

FEP Features, Events and Processes

NAVFAC U.S. Naval Facilities Engineering Command

NRC U.S. Nuclear Regulatory Agency

SCM Software Configuration Management

TIC Technical Information Center

TSPA-LA Total System Performance Assessment for the License Application

USN U.S. Department of Navy

3DEC Three Dimensional Distinct Element Code 
Sampling of Stochastic Input Parameters for Rockfall Calculations and for Structural Response Calculations Under Vibratory Ground Motion

INTENTIONALLY LEFT BLANK 


\section{PURPOSE}

The purpose of this scientific analysis is to define the sampled values of stochastic (random) input parameters for (1) rockfall calculations in the lithophysal and nonlithophysal zones under vibratory ground motions, and (2) structural response calculations for the drip shield and waste package under vibratory ground motions. This analysis supplies:

- Sampled values of ground motion time history and synthetic fracture pattern for analysis of rockfall in emplacement drifts in nonlithophysal rock (Section 6.3 of Drift Degradation Analysis, BSC 2004 [DIRS 166107])

- Sampled values of ground motion time history and rock mechanical properties category for analysis of rockfall in emplacement drifts in lithophysal rock (Section 6.4 of Drift Degradation Analysis, BSC 2004 [DIRS 166107])

- Sampled values of ground motion time history and metal to metal and metal to rock friction coefficient for analysis of waste package and drip shield damage to vibratory motion in Structural Calculations of Waste Package Exposed to Vibratory Ground Motion (BSC 2004 [DIRS 167083]) and in Structural Calculations of Drip Shield Exposed to Vibratory Ground Motion (BSC 2003 [DIRS 163425]).

The sampled values are indices representing the number of ground motion time histories, number of fracture patterns and rock mass properties categories. These indices are translated into actual values within the respective analysis and model reports or calculations.

This report identifies the uncertain parameters and documents the sampled values for these parameters. The sampled values are determined by GoldSim V6.04.007 [DIRS 151202] calculations using appropriate distribution types and parameter ranges. No software development or model development was required for these calculations.

The calculation of the sampled values allows parameter uncertainty to be incorporated into the rockfall and structural response calculations that support development of the seismic scenario for the Total System Performance Assessment for the License Application (TSPA-LA). The results from this scientific analysis also address project requirements related to parameter uncertainty, as specified in the acceptance criteria in Yucca Mountain Review Plan, Final Report (NRC 2003 [DIRS 163274]).

This document was prepared under the direction of Technical Work Plan for: Regulatory Integration Modeling of Drift Degradation, Waste Package and Drip Shield Vibratory Motion and Seismic Consequences (BSC 2004 [DIRS 170528]) which directed the work identified in work package ARTM05. This document was prepared under procedure AP-SIII.9Q, Scientific Analyses. There are no specific known limitations to this analysis. 
Sampling of Stochastic Input Parameters for Rockfall Calculations and for Structural Response Calculations Under Vibratory Ground Motion

\section{INTENTIONALLY LEFT BLANK}




\section{QUALITY ASSURANCE}

The Quality Assurance program applies to the development of this document because this scientific analysis develops data that support performance assessment. Applicability of the Quality Assurance requirements for this document is found in Section 8 of Technical Work Plan for: Regulatory Integration Modeling of Drift Degradation, Waste Package and Drip Shield Vibratory Motion and Seismic Consequences (BSC 2004 [DIRS 170528]). This document has no variances from the Technical Work Plan, and was prepared in accordance with AP-SIII.9Q, Scientific Analyses and reviewed in accordance with AP-2.14Q, Document Review. The input data for this report are identified and tracked in accordance with AP-3.15Q, Managing Technical Product Inputs. The qualified software for this scientific analysis was obtained and used in accordance with LP-SI-11Q-BSC, Software Management. The calculations in this scientific analysis do not provide direct investigation or analysis of structures, systems, or components important to safety as defined by the Q-List (BSC 2004 [DIRS 168361], Table A-2). Methods used to control the electronic management of data, as required by AP-SV.1Q, Control of the Electronic Management of Information, are identified in Section 8 of the technical work plan (BSC 2004 [DIRS 170528]). No variances from the methods to control management of data as required in AP-SV.1Q were performed. 
Sampling of Stochastic Input Parameters for Rockfall Calculations and for Structural Response Calculations Under Vibratory Ground Motion

\section{INTENTIONALLY LEFT BLANK}




\section{USE OF SOFTWARE}

\subsection{QUALIFIED SOFTWARE}

GoldSim was used for these calculations. GoldSim is a qualified code that is appropriate for the intended use and has been used only within its range of validation. GoldSim (GoldSim V6.04.007, STN: 10344-6.04.007-00 [DIRS 151202]) was obtained from Software Configuration Management (SCM) in accordance with LP-SI-11Q-BSC, Software Management. The software was used in the operating environment for which it was baselined by SCM and within the range for which it was validated. Version V6.04.007 of GoldSim was the baseline version of this program at the time analyses presented in previous version (Rev 00) of this report was conducted. The operating environment of the GoldSim software is Windows NT used on an Intel processor-based workstation. GoldSim was selected for use as it provided the capability to perform random sampling of a population of data, because it was in current use and therefore readily available on the Yucca Mountain Project, and because it has undergone quality assurance testing and documentation. The analyses reported in this document, which involve random sampling of populations using a Latin Hypercube sampling method, are within the range of use of this software ${ }^{1}$.

\subsection{EXEMPT SOFTWARE}

Microsoft Excel for Windows, Version 97 SR-2, is used to view the results from the GoldSim calculations. Excel is convenient for presentation of GoldSim output because GoldSim has the ability to write an output file that is compatible with Excel and because Excel is readily available on personal computers throughout the project. No added formulas or algorithms of any kind were executed by Excel and it is not used as a software routine. GoldSim file names resulting from these analyses are identified in Section 6.0. The tabulated data from the Excel files are presented as Microsoft Word tables in the output DTN: MO0301SPASIP27.004. Microsoft Excel 97 SR-2 is an exempt software product in accordance with Section 2.1.1 of LP-SI-11Q-BSC, Software Management.

${ }^{1}$ GoldSim is used to perform a random sampling of parameters in this document. Monte Carlo random sampling methods are typically used for this purpose. Latin Hypercube is a sampling methodology that requires fewer model iterations to approximate the desired variable distribution than the simple Monte Carlo method. The Latin Hypercube technique ensures that the entire range of each variable is sampled. 
Sampling of Stochastic Input Parameters for Rockfall Calculations and for Structural Response Calculations Under Vibratory Ground Motion

\section{INTENTIONALLY LEFT BLANK}




\subsection{DIRECT INPUTS}

\section{INPUTS}

Direct input data to this analysis include the following:

- Input values for the number of ground motion time histories (15) to describe potential variability of frequency content and amplitude. The technical basis for this input is given below.

- Input values for number of lithophysal rock strength categories (5) that cover the expected strength range in situ. The technical basis for this input is given below.

The number of ground motion time histories (15) for post-closure performance assessment is derived from the Development of Earthquake Ground Motion Input for Preclosure Seismic Design and Postclosure Performance Assessment of a Geologic Repository at Yucca Mountain, NV (BSC 2004 [DIRS 168780], Section 6.3.2.4). In that document, 17 sets of three-component time histories were developed for each annual probability of exceedance considered for post-closure analyses. The time histories selected were based on strong motion records chosen to represent the range of earthquake magnitudes and distances indicated by the peak ground velocity hazard analysis (BSC 2004 [DIRS 168780], Table 6.3-9). As explained in that document, 15 sets of input ground motions are recommended by NUREG/CR-6728 (McGuire et al. 2001 [DIRS 157510], p. 3-3) when using a suite of time histories to perform soil-structure interaction analysis that is consistent with a probabilistically-defined seismic hazard. Two extra sets were developed to allow for substitutions if any of the 17 sets were found to be inappropriate. In this case, the response spectrum for the vertical component of set \#15 is an outlier when plotted with the first 16 spectra. It exhibits anomalously low values at high frequencies (greater than about $2 \mathrm{~Hz}$ ) and anomalously high values at low frequencies (less than about $0.2 \mathrm{~Hz}$ ). Because of the anomalous character of set \#15, set \#16 was substituted for it in postclosure analyses. The use of set \#17 as a substitute was not required. The ground motion sets are used in the Drift Degradation Analysis (BSC 2004 [DIRS 166107], Table 6-8 and Table 6-36), in the Structural Calculations of Drip Shield Exposed to Vibratory Ground Motion (BSC 2003 [DIRS 163425], Table 1), and in the Structural Calculations of Waste Package Exposed to Vibratory Ground Motion (BSC 2004 [DIRS 167083], Table 6.1-1).

The number of lithophysal rock compressive strength categories (5) is derived from the Drift Degradation Analysis (BSC 2004 [DIRS 166107], Table 6-33 and Table E-10). The five categories of the lithophysal rock mass strength selected for analyses in that document represent the variability of rock mass quality of lithophysal rock throughout the repository. The categories include "base case" unconfined compressive strengths of 10, 15, 20, 25 and $30 \mathrm{MPa}$, with associated Young's modulus of 1.9, 6.4, 10.8, 15.3 and 19.7 GPa, respectively, which correspond to lithophysal porosities of approximately 35, 28, 21, 13 and 7 percent, and "bounding" unconfined compressive strengths of 10 to 11,10 to 23,10 to 32,13 to 40 , and 16 to $47 \mathrm{MPa}$, respectively. These property categories are based upon laboratory testing of large diameter rock core supplemented by numerical modeling, as described in the Drift Degradation Analysis (BSC 2004 [DIRS 166107], Appendix E, Section E4.1). 
This scientific analysis does not use any previously developed or validated models to perform the analyses described in Section 6.

\subsection{CRITERIA}

General programmatic requirements for this document are listed in Technical Work Plan for: Regulatory Integration Modeling of Drift Degradation, Waste Package and Drip Shield Vibratory Motion and Seismic Consequences (BSC 2004 [DIRS 170528]). The technical work plan specifies that this document must adhere to the requirements of AP-SIII.9Q, Scientific Analyses and that the acceptance criteria in Yucca Mountain Review Plan, Final Report (NRC 2003 [DIRS 163274]) must be addressed.

Project Requirements Document (Canori and Leitner 2003 [DIRS 166275]) contains the technical requirements that provide a basis for criteria relevant to this scientific analysis. The one requirement that is directly relevant to this scientific analysis and its link to 10 CFR Part 63 [DIRS 156605], is defined in Section 3.4 of Project Requirements Document (Canori and Leitner 2003 [DIRS 166275]) as follows:

- PRD-002/T-015: Requirements for Performance Assessment.

Regulation 10 CFR 63.114 specifies technical requirements to be used in a performance assessment to demonstrate compliance to 10 CFR 63.113. It includes requirements for calculations, including data related to site geology, hydrology, and geochemistry; the need to account for uncertainties and variabilities in model parameters, the need to consider alternative conceptual models, and technical bases for inclusion or exclusion of specific FEPs [features, events, and processes], deterioration or degradation processes of engineered barriers, and all the models used in performance assessment.

The acceptance criteria that is relevant to requirement PRD-002/T-015 is found in Section 2.2.1.3.2 of Yucca Mountain Review Plan, Final Report (NRC 2003 [DIRS 163274]). Two subcriteria of the third acceptance criterion in Section 2.2.1.3.2.3 are applicable to this scientific analysis:

- Acceptance Criterion 3: Data Uncertainty is Characterized and Propagated Through the Model Abstraction.

(1) Models use parameter values, assumed ranges, probability distributions, and bounding assumptions that are technically defensible, reasonably account for uncertainties and variabilities, and do not result in an under-representation of the risk estimate.

(2) Uncertainty is adequately represented in parameter development for conceptual models, process-level models, and alternative conceptual models considered in developing the assessment abstraction of mechanical disruption of engineered barriers. This may be done either through sensitivity analyses or use of conservative limits. 
Section 6.5 provides a discussion of how this scientific analysis supports the characterization and propagation of uncertainty in the seismic scenario.

\subsection{CODES, STANDARDS, AND REGULATIONS}

The relevant codes and standards that are applicable to the development of this scientific analysis are 10 CFR Part 63 [DIRS 156605], specifically 10 CFR 63.114. 
Sampling of Stochastic Input Parameters for Rockfall Calculations and for Structural Response Calculations Under Vibratory Ground Motion

\section{INTENTIONALLY LEFT BLANK}




\section{ASSUMPTIONS}

Section 6, Scientific Analysis Discussion, includes a series of decisions that are categorized as "engineering judgments.” Those engineering judgments are cited here as assumptions.

\subsection{MAJOR UNCERTAIN PARAMETERS FOR ROCKFALL MODELING}

Assumption: The analyses in this report assume that the major uncertain parameters in the analysis of drift degradation in response to seismic loading are:

- Ground motion and rock mass fracture geometry (nonlithophysal rock)

- Ground motion and rock compressive strength (lithophysal rock).

Basis: This assumption is required to provide an evaluation of those model input parameters that have greatest level of uncertainty and require stochastic variation of input for rockfall analysis. The basis for this assumption is engineering judgment. The nonlithophysal rock blocks are strong and elastic, and failure response controlled by the natural fracture sets. The lithophysal rock has lower strength and ubiquitous, small scale fracturing, and the failure mechanism is controlled by the overall rock mass strength. Therefore, the applied stress (via the ground motion) and the features that control yield (fractures in the nonlithophysal rock and rock mass strength in the lithophysal rock) are the major uncertain parameters.

Confirmation Status: This assumption was confirmed in Drift Degradation Analyses (BSC 2004 [DIRS 166107]). Parametric analyses of rockfall presented in this document confirmed that fracture geometry and ground motion time history are the critical parameters that control rockfall in the nonlithophysal rock mass (Section 6.3) and that rock mass strength and ground motion time history are the most important parameters controlling drift degradation in lithophysal rocks (Section 6.5). Confirmation was achieved via a parametric sensitivity study that was performed in which input data to the rockfall models was varied to examine their impact on rockfall. The input varied included: a) in situ stress state (to represent depth of emplacement drift), b) rock mechanical properties (strength and moduli), c) rock thermal properties (thermal conductivity, heat capacity and thermal expansion coefficient) as well as the ground motion, rock fracture geometry and properties (nonlithophysal rock) and rock mass strength (lithophysal rock). Section 6.5 of BSC 2004 [DIRS 166107] identifies ground motion time history, rock fracture geometry and rock mass strength category as the most important uncertain parameters in control of drift degradation response.

Use in the Analysis/Model: This assumption is used in Sections 6.1.1 and 6.3.1.

\subsection{NUMBER OF REALIZATIONS FOR ROCKFALL ANALYSES}

Assumption: The seismic-induced rockfall analyses in nonlithophysal rock are deterministic in nature - i.e., an analysis of an emplacement drift located within a given fracture geometry, subjected to a given ground motion time history is performed. To obtain a statistically relevant representation of the mean rockfall result and its variability, the number of deterministic simulations need to be defined. In Section 4.1, the number of time histories required to represent the ground motion variability (15) was described. The number of distinct fracture patterns that 
must be defined to capture the stochastic variability of the rockfall is also required. A sampling of 30 fracture geometries was originally chosen to describe the stochastic variability of rockfall. It was found that 30 samples were insufficient to describe the variability (BSC 2004 [DIRS 166107], Appendix K), so an additional sampling was performed to provide additional fracture geometries. To this end, an additional sampling of 105 different possible fracture geometries is assumed to be sufficient to describe the impact of fracture network geometry variability in the nonlithophysal rock on rockfall due to seismic loading.

In the lithophysal rock, a total 30 samples of ground motion and rock strength category were chosen as sufficient to examine the sensitivity of emplacement drift damage level (in terms of mass or volume) to the peak ground velocity associated with the ground motion. The numerical analyses conducted to estimate drift damage in lithophysal rock is deterministic in nature and is aimed at examining the bounding ranges of damage associated with the ground motion amplitudes and rock mass strength categories. Therefore, the sampling simply needs to provide an adequate pairing of ground motion time histories and rock mass strength categories that span their range.

Basis: .The sampling of 105 fracture geometries is based on engineering judgment as a sufficient number of realizations for representation of the variability in fracture patterns in the nonlithophysal rock mass. The sampling of 30 ground motion time histories and rock mass strength categories is based on engineering judgment.

Confirmation Status: The assumption of 105 fracture patterns was confirmed in Drift Degradation Analysis (BSC 2004 [DIRS 166107], Appendix K). Analyses showed that 50 realizations of fracture geometries were sufficient to represent the variability of fracture pattern based on determination of the mean and standard deviation of rockfall mass and total volume as a function of the number of realizations. Therefore, the 105 samplings provided were sufficient to describe rock fracture pattern variability. The assumption of 30 pairings of ground motion time histories with rock strength categories was confirmed in Drift Degradation Analysis (BSC 2004 [DIRS 166107], Section 6.4). Analyses with postclosure ground motions with probability of annual exceedance of $1 \times 10^{-5}$ and $1 \times 10^{-6}$ were conducted. The emplacement drifts collapse for all of the $1 \times 10^{-6}$ and some of the $1 \times 10^{-5}$ time histories. Therefore, the $1 \times 10^{-7}$ analyses proved unnecessary since the ground motions are of greater amplitude and will also result in complete collapse. In order to more accurately describe the damage at the $1 \times 10^{-5}$ annual exceedance probability, it was determined to perform analyses for all of the 15 time histories for strength categories 1,3 and 5 , thus covering the entire range of rock mass strength. Therefore, the sampling strategy was ultimately unimportant in the analyses.

Use in the Analysis/Model: This assumption is used in Sections 6.1.2, 6.2.1, 6.3.1 and 6.3.2.

\subsection{MAJOR UNCERTAIN PARAMETERS FOR VIBRATORY STRUCTURAL ANALYSIS}

Assumption: The major uncertain parameters for structural response of the waste package and drip shield to vibratory motion are: the ground motion time history, metal-to-metal friction coefficient, and metal-to-rock friction coefficient. 
Basis: The ground motion time histories (accelerograms) are the major source of damage to the drip shield and waste package in the seismic scenario. The metal-to-metal and metal-to-rock friction coefficients determine the ease of sliding between EBS components during an earthquake, and has potential to affect the coupling of energy from the ground motions to the drip shield and waste package. The identification of these parameters is based on engineering judgment presented in the Structural Calculations of Drip Shield Exposed to Vibratory Ground Motion (BSC 2003 [DIRS 163425], Section 3) and Structural Calculations of Waste Package Exposed to Vibratory Ground Motion (BSC 2004 [DIRS 167083], Section 3).

Confirmation Status: This assumption does not require further confirmation. As stated in the Structural Calculations of Drip Shield Exposed to Vibratory Ground Motion (BSC 2003 [DIRS 163425], Section 3) and Structural Calculations of Waste Package Exposed to Vibratory Ground Motion (BSC 2004 [DIRS 167083], Section 3), the appropriate coefficients of friction for the repository components have high uncertainty. Therefore, it is appropriate to pick a distribution of values for the coefficients of friction that encompass a range of materials and a range of mechanical responses from little or no sliding between components to substantial sliding between components. No other parameters were indicated in those documents to have a high uncertainty.

Use in the Analysis/Model: This assumption is used in Sections 6.4.1.

\subsection{FRICTION COEFFICIENTS AS INPUT TO VIBRATORY STRUCTURAL ANALYSIS}

Assumption: The range of values for the rock-to-metal friction coefficient and for the metal-to-metal friction coefficient is 0.2 to 0.8 .

Basis: The range of values for the metal-to-metal friction coefficient and for the rock-to-metal friction coefficient are based on handbook data for static and sliding friction coefficients in Marks' Standard Handbook for Mechanical Engineers (Avallone and Baumeister 1987 [DIRS 103508], Table 3.2.1) and in American Institute of Physics Handbook (Gray 1972 [DIRS 138541], pp. 2-42 to 2-46). The above referenced handbooks provide coefficients of static and sliding friction for various metallic and non-metallic materials. However, coefficients of friction for Alloy 22 (outer shell of the waste package and the emplacement pallet), for Titanium Grade 7 (for the drip shield), and for rock (crushed tuff in the invert) are not specifically mentioned in these handbooks. When defining the friction coefficient, it is important to consider the potential for long-term corrosion to modify the sliding friction of Alloy 22 and Titanium Grade 7. In this situation, the appropriate coefficients of friction for the metal-to-metal contact between the waste package and emplacement pallet, and for the metal-to-rock contact between the invert and the emplacement pallet and/or drip shield have high uncertainty. It is appropriate to pick a distribution of values for the coefficients of friction that encompass a range of materials, thereby providing a range of mechanical response, from little or no sliding between components to substantial sliding between components. The range of values chosen, 0.2 to 0.8 , is a conservative range of friction coefficient that covers a range from low friction sliding to little or no sliding. The range of friction coefficient from 0.2 to 0.8 encompasses the values for steel sheet pile to rock contact of 0.30 ("single size hard rock 
fill”) and 0.40 ("clean gravel” and "well-graded rock fill with spalls") cited in USN 1986 [DIRS 102312], Chapter 3, Table 1).

Confirmation Status: This assumption does not require further confirmation. In this situation, the appropriate coefficients of friction for the metal-to-metal contact between the waste package and emplacement pallet, and for the metal-to-rock contact between the invert and the emplacement pallet and/or drip shield have high uncertainty. It is appropriate to pick a distribution of values for the coefficients of friction that encompass a range of materials, thereby providing a range of mechanical response, from little or no sliding between components to substantial sliding between components.

Use in the Analysis/Model: This assumption is used in Section 6.4.2.

\subsection{USE OF UNIFORM DISTRIBUTION FOR FRICTION COEFFICIENTS FOR VIBRATORY STRUCTURAL ANALYSIS}

Assumption: Use of uniform distribution for description of the variability of the friction coefficients.

Basis: A uniform distribution of values between 0.2 and 0.8 (from a full range of values of 0.15 to 1.4) was selected as the appropriate range of friction coefficients for these calculations. First, this distribution is broad enough to encompass typical values of the dry sliding friction coefficients for a wide variety of materials (Avallone and Baumeister 1987 [DIRS 103508], Table 3.2.1; Gray 1972 [DIRS 138541], Section 2d). This distribution is also broad enough to represent a range of mechanical response for the emplacement pallet, waste package, and drip shield. A friction coefficient near 0.2 allows substantial sliding of the waste package on the emplacement pallet, of the emplacement pallet on the invert, and of the drip shield on the invert. Similarly, a friction coefficient near 0.8 does not allow substantial sliding among the engineered barrier system components and the invert.

Confirmation Status: This assumption does not require further confirmation. The range of friction coefficient of 0.2 to 0.8 assuming a uniform distribution is conservative and bounding because (1) the upper and lower bounds represent a wide range, (2) a uniform distribution was selected instead of a normal or log normal distribution, thereby giving equal weight to low friction coefficients, and (3) reasonable values for unlubricated steel and iron are in the range of 0.4 or even 0.5 , and values for rock-to-metal are in the range of 0.3 or 0.4 , based on the cited references in Section 5.4.

Use in the Analysis/Model: This assumption is used in Section 6.4.2. 


\section{SCIENTIFIC ANALYSIS DISCUSSION}

This section presents the results of four GoldSim calculations that define sampled values of stochastic (random) input parameters for rockfall calculations and for structural response calculations under vibratory ground motions. GoldSim is a qualified code that is appropriate for sampling stochastic parameters. No changes to the GoldSim software are required for these calculations because parameter sampling is a basic capability of the GoldSim software. These calculations only require definition of the distribution types and ranges for the stochastic parameters; no model is necessary for these calculations. The four calculations are as follows:

- Rockfall_NonLith_Stoch_Input.gsm. This calculation produced the initial sampling of stochastic input parameters for rockfall calculations in the nonlithophysal zone. The sampled input parameters used as input to this scientific analysis are ground motion time history number and synthetic fracture pattern number. Thirty realizations are performed. A printout of the Excel file with the results from this calculation is in DTN: MO0301SPASIP27.004 in the files under System Performance Assessment Data Set File: Sampling.Description.Doc/Attachment 1 /Table titled: Rockfall_NonLith_Stoch_Input.xls .

- Rockfall_NonLith2_Stoch_Input.gsm. This calculation produced the second sampling of stochastic input parameters for rockfall calculations in the nonlithophysal zone. The stochastic input parameters used as input to this scientific analysis are ground motion time history number and synthetic fracture pattern number. One hundred and five realizations are performed. A second sampling has been performed for rockfall in the nonlithophysal zone because the initial rockfall calculations demonstrated that more realizations are required to properly capture the variability of rockfall to the synthetic fracture pattern number and its geometry. A printout of the Excel file with the results from this calculation is in DTN: MO0301SPASIP27.004 in the files under System Performance Assessment Data Set File: Sampling.Description.Doc/Attachment 1/Table titled: Rockfall_NonLith2_Stoch_Input.xls .

- Rockfall_Lith_Stoch_Input.gsm. This calculation produced the sampling of stochastic input parameters for rockfall calculations in the lithophysal zone. The stochastic input parameters used as input to this scientific analysis are ground motion time history number and the rock compressive strength index (also denoted as the rock quality number in Table I-3 DTN: MO0301SPASIP27.004). Thirty realizations are performed. A printout of the Excel file with the results from this calculation is in DTN: MO0301SPASIP27.004 in the files under System Performance Assessment Data Set File: Sampling.Description.Doc/Attachment 1/Table titled: Rockfall_Lith_Stoch_Input.xls.

- WP_Stoch_Input.gsm. This calculation produced the sampling of stochastic input parameters for structural response calculations for vibratory ground motions. The stochastic input parameters used as input to this scientific analysis are ground motion time history number, metal-to-metal friction coefficient, and metal-to-rock friction coefficient. Fifteen realizations are performed. A printout of the Excel file with the results from this calculation is in DTN: MO0301SPASIP27.004 in the files under System 
Performance Assessment Data Set File: Sampling.Description.Doc, Attachment 1, Table titled: WP_Stoch_Input.xls.

After the GoldSim calculations were completed, ground motion time history \#16 was substituted for history \#15. As described in Section 4.1, time history \#15 has an unusual spectral acceleration curve, and time history \#16 was therefore substituted for \#15 in the rockfall and structural response calculations. The change from time history \#15 to \#16 does not invalidate the original GoldSim sampling calculations. This change is directly incorporated into Tables 6-1 through 6-4 that presents the computational results in this section. The original GoldSim outputs, without adjustment, are documented in DTN: MO0301SPASIP27.004, Attachment 1.

\subsection{INITIAL SAMPLING FOR ROCKFALL CALCULATIONS IN THE NONLITHOPHYSAL ZONE}

\subsubsection{Identification of Uncertain Parameters}

The major uncertain parameters for rockfall calculations in the nonlithophysal zone are the ground motion and the synthetic fracture pattern. The ground motion time histories (accelerograms) are the major source for damage to the host rock in the seismic scenario. The synthetic fracture pattern (fracture geometry) determines the geometry of rock blocks in the emplacement drift periphery and the potential for rockfall occurring as a result of the ground motion. The identification of these parameters as important to drift stability is based on engineering judgment, as presented in the Drift Degradation Analysis (BSC 2004 [DIRS 166107], Section 6.5) and summarized in Section 4.1. The importance of fracture geometry and ground motion time history in controlling rockfall in nonlithophysal units was confirmed in Section 6.3.1.2 of the Drift Degradation Analysis (BSC 2004 [DIRS 166107]).

Uncertainty in the ground motion is represented by 15 time histories. The use of 15 ground motion time histories follows the recommendation in NUREG/CR-6728 (McGuire, et. al. 2001 [DIRS 157510], p. 3-3) for performing soil-structure interaction analyses that are consistent with a probabilistically defined seismic hazard, as discussed in Section 4.1. Uncertainty in the synthetic fracture pattern is initially represented by 30 fracture geometries. However, as noted in Section 4.1, the number of fracture geometries finally selected was 105, as explained in the Drift Degradation Analysis (BSC 2004 [DIRS 166107], Section 6.3.1.2.2 and Appendix J). ${ }^{2}$

\subsubsection{Computational Results}

This calculation produced the initial sampling of stochastic input parameters for rockfall calculations in the nonlithophysal zone. There are 30 realizations for this GoldSim analysis,

\footnotetext{
${ }^{2}$ Verification of the number of fracture geometries required to provide a representative prediction of the variability of rockfall for a given set of 15 ground motions is described in Drift Degradation Analysis (BSC 2004 [DIRS 166107], Appendix K). Summary statistics (mean, median, maximum and standard deviation) of the rockfall parameters (i.e., block size, impact velocity and impact energy) were determined for the cumulative rockfall as a function of the number of analyses (i.e., fracture geometries) conducted. It was found that these parameters approached asymptotic values after approximately 30 to 35 analyses. Thus, this verification indicated that the impact of the variability of fracture pattern on rockfall parameters is represented with less than 50 analyses.
} 
using a Monte Carlo approach with Latin Hypercube sampling. The two stochastic parameters for this analysis are:

Ground Motion Time History Number

Synthetic Fracture Pattern Number
Discrete distribution with the values $1,2,3, \ldots, 14$ and 15; each value is equally probable.

Discrete distribution with the values 1, 2, 3, .., 29 and 30 ; each value is equally probable.

The GoldSim results, with time history \#15 replaced by \#16, are shown in Table 6-1.

Table 6-1. First Sampling of Input Values for Rockfall Calculations in the Nonlithophysal Zone as a Result of the GoldSim Calculations

\begin{tabular}{|c|c|c|}
\hline $\begin{array}{l}\text { Realization } \\
\text { Number }\end{array}$ & $\begin{array}{c}\text { Ground Motion Time } \\
\text { History Number }\end{array}$ & $\begin{array}{l}\text { Synthetic Fracture } \\
\text { Pattern Number }\end{array}$ \\
\hline 1 & 4 & 15 \\
\hline 2 & 8 & 29 \\
\hline 3 & 16 & 24 \\
\hline 4 & 12 & 4 \\
\hline 5 & 2 & 16 \\
\hline 6 & 8 & 28 \\
\hline 7 & 14 & 8 \\
\hline 8 & 4 & 20 \\
\hline 9 & 10 & 11 \\
\hline 10 & 6 & 18 \\
\hline 11 & 9 & 1 \\
\hline 12 & 1 & 2 \\
\hline 13 & 1 & 13 \\
\hline 14 & 7 & 22 \\
\hline 15 & 11 & 21 \\
\hline 16 & 11 & 30 \\
\hline 17 & 16 & 27 \\
\hline 18 & 14 & 26 \\
\hline 19 & 13 & 10 \\
\hline 20 & 5 & 19 \\
\hline 21 & 10 & 9 \\
\hline 22 & 5 & 23 \\
\hline 23 & 12 & 5 \\
\hline 24 & 3 & 6 \\
\hline 25 & 3 & 17 \\
\hline 26 & 9 & 12 \\
\hline 27 & 6 & 14 \\
\hline
\end{tabular}


Table 6-1. First Sampling of Input Values for Rockfall Calculations in the Nonlithophysal Zone as a Result of the GoldSim Calculations (Continued)

\begin{tabular}{|c|c|c|}
\hline $\begin{array}{c}\text { Realization } \\
\text { Number }\end{array}$ & $\begin{array}{c}\text { Ground Motion Time } \\
\text { History Number }\end{array}$ & $\begin{array}{c}\text { Synthetic Fracture } \\
\text { Pattern Number }\end{array}$ \\
\hline 28 & 7 & 25 \\
\hline 29 & 13 & 3 \\
\hline 30 & 2 & 7 \\
\hline
\end{tabular}

Source: DTN: MO0301SPASIP27.004 in the files under System Performance Assessment Data Set File:

Sampling.Description.Doc, Table I-1. First Sampling of Input Values for the 3DEC Calculations for Rockfall Calculations in the Nonlithophysal Zone.

\subsection{SECOND SAMPLING FOR ROCKFALL CALCULATIONS IN THE NONLITHOPHYSAL ZONE}

\subsubsection{Identification of Uncertain Parameters}

The major uncertain parameters for rockfall calculations in the nonlithophysal zone are the ground motion and the synthetic fracture pattern. The ground motion time histories (accelerograms) are the major source for damage to the host rock in the seismic scenario. The synthetic fracture pattern (fracture geometry) determines the geometry of key blocks and whether or not blocks are ejected during the ground motion. Uncertainty in the ground motion is represented by 15 time histories. Uncertainty in the synthetic fracture pattern is represented by 105 fracture geometries. The use of 105 fracture geometries is based on the results from rockfall calculations with 30 fracture geometries, where it was observed that fracture geometry was a dominant parameter and additional variability was required to accurately represent the range of rock blocks that have the potential to be ejected during a seismic event.

\subsubsection{Computational Results}

This calculation produced the second sampling of stochastic input parameters for rockfall calculations in the nonlithophysal zone. There are 105 realizations for this GoldSim analysis, using a Monte Carlo approach with Latin Hypercube sampling. This second sampling is designed to more carefully evaluate the effect of synthetic fracture pattern on rockfall. The two stochastic parameters for this analysis are:

Ground Motion Time History Number

Synthetic Fracture Pattern Number
Discrete distribution with the values $1,2,3, \ldots, 14$ and 15; each value is equally probable.

Discrete distribution with the values 1, 2, 3, .., 104 and 105; each value is equally probable.

The GoldSim results, with time history \#15 replaced by \#16, are shown in Table 6-2. 
Sampling of Stochastic Input Parameters for Rockfall Calculations and for

Structural Response Calculations Under Vibratory Ground Motion

Table 6-2. Second Sampling of Input Values for Rockfall Calculations in the Nonlithophysal Zone as a Result of the GoldSim Calculations

\begin{tabular}{|c|c|c|}
\hline $\begin{array}{c}\text { Realization } \\
\text { Number }\end{array}$ & $\begin{array}{l}\text { Ground Motion Time } \\
\text { History Number }\end{array}$ & $\begin{array}{c}\text { Synthetic Fracture } \\
\text { Pattern Number }\end{array}$ \\
\hline 1 & 16 & 79 \\
\hline 2 & 12 & 7 \\
\hline 3 & 1 & 102 \\
\hline 4 & 16 & 75 \\
\hline 5 & 11 & 33 \\
\hline 6 & 5 & 78 \\
\hline 7 & 12 & 15 \\
\hline 8 & 3 & 29 \\
\hline 9 & 5 & 37 \\
\hline 10 & 6 & 99 \\
\hline 11 & 16 & 42 \\
\hline 12 & 6 & 24 \\
\hline 13 & 4 & 59 \\
\hline 14 & 9 & 65 \\
\hline 15 & 10 & 39 \\
\hline 16 & 6 & 50 \\
\hline 17 & 8 & 103 \\
\hline 18 & 16 & 35 \\
\hline 19 & 5 & 57 \\
\hline 20 & 9 & 67 \\
\hline 21 & 10 & 63 \\
\hline 22 & 9 & 82 \\
\hline 23 & 12 & 4 \\
\hline 24 & 1 & 83 \\
\hline 25 & 12 & 16 \\
\hline 26 & 3 & 98 \\
\hline 27 & 14 & 28 \\
\hline 28 & 4 & 8 \\
\hline 29 & 2 & 74 \\
\hline 30 & 11 & 80 \\
\hline 31 & 12 & 81 \\
\hline 32 & 12 & 71 \\
\hline 33 & 11 & 96 \\
\hline 34 & 14 & 49 \\
\hline 35 & 7 & 20 \\
\hline 36 & 3 & 62 \\
\hline 37 & 9 & 41 \\
\hline 38 & 6 & 69 \\
\hline 39 & 10 & 11 \\
\hline 40 & 2 & 54 \\
\hline 41 & 8 & 104 \\
\hline 42 & 16 & 36 \\
\hline
\end{tabular}


Sampling of Stochastic Input Parameters for Rockfall Calculations and for

Structural Response Calculations Under Vibratory Ground Motion

Table 6-2. Second Sampling of Input Values for Rockfall Calculations in the Nonlithophysal Zone as a Result of the GoldSim Calculations (Continued)

\begin{tabular}{|c|c|c|}
\hline $\begin{array}{l}\text { Realization } \\
\text { Number }\end{array}$ & $\begin{array}{l}\text { Ground Motion Time } \\
\text { History Number }\end{array}$ & $\begin{array}{c}\text { Synthetic Fracture } \\
\text { Pattern Number }\end{array}$ \\
\hline 43 & 6 & 53 \\
\hline 44 & 8 & 94 \\
\hline 45 & 14 & 92 \\
\hline 46 & 14 & 68 \\
\hline 47 & 10 & 48 \\
\hline 48 & 7 & 18 \\
\hline 49 & 3 & 1 \\
\hline 50 & 1 & 93 \\
\hline 51 & 14 & 84 \\
\hline 52 & 12 & 91 \\
\hline 53 & 13 & 90 \\
\hline 54 & 13 & 2 \\
\hline 55 & 1 & 100 \\
\hline 56 & 16 & 13 \\
\hline 57 & 2 & 73 \\
\hline 58 & 11 & 43 \\
\hline 59 & 7 & 72 \\
\hline 60 & 11 & 105 \\
\hline 61 & 16 & 22 \\
\hline 62 & 4 & 21 \\
\hline 63 & 3 & 30 \\
\hline 64 & 5 & 27 \\
\hline 65 & 4 & 26 \\
\hline 66 & 4 & 10 \\
\hline 67 & 2 & 88 \\
\hline 68 & 13 & 52 \\
\hline 69 & 8 & 86 \\
\hline 70 & 13 & 85 \\
\hline 71 & 13 & 19 \\
\hline 72 & 3 & 77 \\
\hline 73 & 11 & 56 \\
\hline 74 & 8 & 45 \\
\hline 75 & 7 & 40 \\
\hline 76 & 6 & 89 \\
\hline 77 & 13 & 9 \\
\hline 78 & 2 & 23 \\
\hline 79 & 4 & 47 \\
\hline 80 & 7 & 5 \\
\hline 81 & 1 & 44 \\
\hline 82 & 7 & 55 \\
\hline 83 & 8 & 6 \\
\hline 84 & 1 & 34 \\
\hline
\end{tabular}


Table 6-2. Second Sampling of Input Values for Rockfall Calculations in the Nonlithophysal Zone as a Result of the GoldSim Calculations (Continued)

\begin{tabular}{|c|c|c|}
\hline $\begin{array}{c}\text { Realization } \\
\text { Number }\end{array}$ & $\begin{array}{c}\text { Ground Motion Time } \\
\text { History Number }\end{array}$ & $\begin{array}{c}\text { Synthetic Fracture } \\
\text { Pattern Number }\end{array}$ \\
\hline 85 & 5 & 17 \\
\hline 86 & 3 & 97 \\
\hline 87 & 14 & 46 \\
\hline 88 & 7 & 95 \\
\hline 89 & 14 & 38 \\
\hline 90 & 6 & 31 \\
\hline 91 & 5 & 64 \\
\hline 92 & 10 & 76 \\
\hline 93 & 11 & 12 \\
\hline 94 & 2 & 14 \\
\hline 95 & 2 & 25 \\
\hline 96 & 4 & 70 \\
\hline 97 & 10 & 51 \\
\hline 98 & 8 & 61 \\
\hline 99 & 9 & 60 \\
\hline 100 & 9 & 87 \\
\hline 101 & 13 & 3 \\
\hline 102 & 1 & 32 \\
\hline 103 & 5 & 58 \\
\hline 104 & 9 & 66 \\
\hline 105 & 10 & 101 \\
\hline
\end{tabular}

Source: DTN: MO0301SPASIP27.004 in the files under System Performance Assessment Data Set File:

Sampling.Description.Doc, Table I-2. Second Sampling of Input Values for Rockfall Calculations in the Nonlithophysal Zone.

\subsection{SAMPLING FOR ROCKFALL CALCULATIONS IN THE LITHOPHYSAL ZONE}

\subsubsection{Identification of Uncertain Parameters}

The major uncertain parameters for rockfall calculations in the lithophysal zone are the ground motion and the rock mechanical properties that include Young's modulus and compressive strength. The ground motion time histories (accelerograms) are the major source of damage to the host rock in the seismic scenario. The rock mechanical properties determine the elastic-plastic response of the lithophysal rock, particularly if and when failure occurs during the ground motions. The identification of these parameters is based on engineering judgment, as presented in the Drift Degradation Analysis (BSC 2004 [DIRS 166107], Section 6.5) and summarized in Section 4.1.

The uncertainty in the ground motion is adequately represented by 15 time histories. The use of 15 ground motion time histories follows the recommendation in NUREG/CR-6728 (McGuire et al. 2001 [DIRS 157510], p. 3-3) for performing soil-structure interaction analyses that are 
consistent with a probabilistically defined seismic hazard, as discussed in Section 4.1. Uncertainty in the rock compressive strength is represented by 5 levels, as noted in Section 4.1, and as explained in the Drift Degradation Analysis (BSC 2004 [DIRS 166107], Section 6.4.1.2 and Appendix E, Section E4.1). The use of 5 rock strength categories provides a high value, and low value, and three levels in between these extremes. The use of 5 levels was shown to be an acceptable method for determining sensitivity of rockfall in the lithophysal zone to variations in rock compressive strength, as explained in the Drift Degradation Analysis (BSC 2004 [DIRS 166107], Appendix E). A deterministic sensitivity study, rather than a stochastic based uncertainty analysis, is used to determined rockfall in the lithophysal rock in the Drift Degradation Analysis (BSC 2004 [DIRS 166107]). The objective of this sensitivity study is to define the relationship of damage in the form of the mass or volume of displaced rock from the tunnel periphery as a function of the peak ground velocity of a given ground motion time history. As a result of this approach, it is important that the sampling strategy select rock compressive strength categories that cover the entire range of strength categories from 1 (lowest strength) to 5 (highest strength).

\subsubsection{Computational Results}

This calculation produced the sampling of stochastic input parameters for rockfall calculations in the lithophysal zone. There are 30 realizations for this GoldSim analysis, using a Monte Carlo approach with Latin Hypercube sampling. The two stochastic parameters for this analysis are:

Ground Motion Time History Number

Rock Compressive Strength Index
Discrete distribution with the values $1,2,3, \ldots, 14$ and 15 ; each value is equally probable.

Discrete distribution with the values 1, 2, 3, 4, and 5; each value is equally probable.

The GoldSim results, with time history \#15 replaced by \#16 (as explained in Section 4.1) and modified to eliminate duplications are shown in Table 6-3.

The GoldSim calculations produced identical sampling for time histories 5, 6, 8, 10, and 12 . These duplicates have been eliminated by changing the second occurrence of each sampled pair as follows: $(5,4)$ was changed to $(5,2),(6,3)$ was changed to $(6,1),(8,5)$ was changed to $(8,1)$, $(10,2)$ was changed to $(10,4)$, and $(12,1)$ was changed to $(12,5)$. The general pattern was to change a high value of the compressive strength index to a corresponding lower value relative to the median compressive strength index (value $=3$ ), and vice versa. In other words, a value of 4 or 5 for the index was changed to 2 or 1 , respectively, and vice versa. If the middle value of compressive strength (value of 3 ) was duplicated, it was replaced with the lowest compressive strength (value of 1 ). The resulting sampling is judged adequate because it maintains reasonable variability in the input values for rock compressive strength.

An alternative to modifying the duplicate samples is to entirely resample the parameter space in such a manner as to eliminate any duplication. This approach was determined to be unnecessary because the rock in the lithophysal zone generally has relatively low compressive strength, even for the highest strength index (index $=5$ ). In this situation, the results from the rockfall calculations in the lithophysal zone were anticipated to be more sensitive to variability in ground 
Sampling of Stochastic Input Parameters for Rockfall Calculations and for Structural Response Calculations Under Vibratory Ground Motion

motion time histories rather than rock compressive strength. Therefore, the approach used was determined to be adequate as the initial sampling strategy, rather than resampling the parameter space.

Table 6-3. Input Values for Rockfall Calculations in the Lithophysal Zone as a Result of the GoldSim Calculations

\begin{tabular}{|c|c|c|}
\hline $\begin{array}{c}\text { Realizatio } \\
\text { Number }\end{array}$ & $\begin{array}{l}\text { Ground Motion Time } \\
\text { History Number }\end{array}$ & $\begin{array}{l}\text { Rock Compressive } \\
\text { Strength Index }\end{array}$ \\
\hline 1 & 4 & 3 \\
\hline 2 & 8 & 5 \\
\hline 3 & 16 & 4 \\
\hline 4 & 12 & 1 \\
\hline 5 & 2 & 3 \\
\hline 6 & 8 & 1 \\
\hline 7 & 14 & 2 \\
\hline 8 & 4 & 4 \\
\hline 9 & 10 & 2 \\
\hline 10 & 6 & 3 \\
\hline 11 & 9 & 1 \\
\hline 12 & 1 & 1 \\
\hline 13 & 1 & 3 \\
\hline 14 & 7 & 4 \\
\hline 15 & 11 & 4 \\
\hline 16 & 11 & 5 \\
\hline 17 & 16 & 5 \\
\hline 18 & 14 & 5 \\
\hline 19 & 13 & 2 \\
\hline 20 & 5 & 4 \\
\hline 21 & 10 & 4 \\
\hline 22 & 5 & 2 \\
\hline 23 & 12 & 5 \\
\hline 24 & 3 & 1 \\
\hline 25 & 3 & 3 \\
\hline 26 & 9 & 2 \\
\hline 27 & 6 & 1 \\
\hline 28 & 7 & 5 \\
\hline 29 & 13 & 1 \\
\hline 30 & 2 & 2 \\
\hline \multicolumn{3}{|c|}{$\begin{array}{l}\text { DTN: MO0301SPASIP27.004 in the files under } \\
\text { System Performance Assessment Data Set File: } \\
\text { Sampling.Description.Doc, Table I-3. Input Values for } \\
\text { Rockfall Calculations in the Lithophysal Zone. }\end{array}$} \\
\hline
\end{tabular}




\subsection{SAMPLING FOR STRUCTURAL RESPONSE CALCULATIONS}

\subsubsection{Identification of Uncertain Parameters}

The major uncertain parameters for the structural response calculations are the ground motion, the metal-to-metal friction coefficient, and the metal-to-rock friction coefficient. The ground motion time histories (accelerograms) are the major source of damage to the drip shield and waste package in the seismic scenario. The metal-to-metal and metal-to-rock friction coefficients determine the ease of sliding between EBS components during an earthquake, and have the potential to affect the coupling of energy from the ground motions to the drip shield and waste package. The identification of these parameters is based on engineering judgment presented in the Structural Calculations of Drip Shield Exposed to Vibratory Ground Motion (BSC 2003 [DIRS 163425], Section 3) and Structural Calculations of Waste Package Exposed to Vibratory Ground Motion (BSC 2004 [DIRS 167083], Section 3).

The uncertainty in the ground motion is represented by 15 time histories. The use of 15 ground motion time histories follows the recommendation in NUREG/CR-6728 (McGuire et al. 2001 [DIRS 157510], p.3-3) for performing soil-structure interaction analyses that are consistent with a probabilistically defined seismic hazard, as discussed in Section 4.1. The rationale for the range of values for the rock-to-metal friction coefficient and for the metal-to-metal friction coefficient, defined as 0.2 to 0.8 , is explained in Section 4.1.

\subsubsection{Computational Results}

This calculation produced the sampling of stochastic input parameters for structural response calculations for vibratory ground motions. There are 15 realizations for this GoldSim analysis, using a Monte Carlo approach with Latin Hypercube sampling. The three stochastic parameters for this analysis are:

Ground Motion Time History Number

Friction Coefficient - Metal-to-Metal

Friction Coefficient - Metal-to-Rock
Discrete distribution with the values $1,2,3, \ldots, 14$ and 15 ; each value is equally probable.

Uniform distribution from 0.2 to 0.8

Uniform distribution from 0.2 to 0.8

The GoldSim results, with time history \#15 replaced by \#16, are shown in Table 6-4. 
Table 6-4. Input Values for Structural Response Calculations as a Result of the GoldSim Calculations

\begin{tabular}{|c|c|c|c|}
\hline $\begin{array}{c}\text { Realization } \\
\text { Number }\end{array}$ & $\begin{array}{c}\text { Ground Motion Time } \\
\text { History Number }\end{array}$ & $\begin{array}{c}\text { Friction Coefficient - } \\
\text { Metal-to-Metal Contact }\end{array}$ & $\begin{array}{c}\text { Friction Coefficient - } \\
\text { Metal-to-Rock Contact }\end{array}$ \\
\hline 1 & 7 & 0.79752 & 0.34489 \\
\hline 2 & 16 & 0.33145 & 0.49001 \\
\hline 3 & 4 & 0.49638 & 0.61575 \\
\hline 4 & 8 & 0.60222 & 0.21821 \\
\hline 5 & 11 & 0.20064 & 0.24159 \\
\hline 6 & 1 & 0.2684 & 0.69338 \\
\hline 7 & 2 & 0.71214 & 0.59525 \\
\hline 8 & 13 & 0.56125 & 0.54137 \\
\hline 9 & 10 & 0.5487 & 0.36358 \\
\hline 10 & 9 & 0.36065 & 0.41037 \\
\hline 11 & 5 & 0.42112 & 0.66615 \\
\hline 12 & 6 & 0.65 & 0.73241 \\
\hline 13 & 12 & 0.74749 & 0.31276 \\
\hline 14 & 14 & 0.28943 & 0.45373 \\
\hline 15 & 3 & 0.45695 & 0.77581 \\
\hline
\end{tabular}

Source: DTN: MO0301SPASIP27.004 in the files under System Performance Assessment Data Set File: Sampling.Description.Doc, Table 1-4. Input values for Structural Response Calculations for Vibratory Ground Motion.

\subsection{DISCUSSION OF YUCCA MOUNTAIN REVIEW PLAN ACCEPTANCE CRITERIA}

As noted in Section 4.2, there are two subcriteria of Acceptance Criterion 3 of Yucca Mountain Review Plan Final Report (NRC 2003 [DIRS 163274]) that are directly relevant to this analysis:

(1) Models use parameter values, assumed ranges, probability distributions, and bounding assumptions that are technically defensible, reasonably account for uncertainties and variability, and do not result in an under-representation of the risk estimate.

(2) Uncertainty is adequately represented in parameter development for conceptual models, process-level models, and alternative conceptual models considered in developing the assessment abstraction of mechanical disruption of engineered barriers. This may be done either through sensitivity analyses or use of conservative limits.

The results of this scientific analysis are specifically designed to represent uncertainty and variability in the values of key input parameters for the rockfall calculations and structural response calculations that support the seismic scenario. The selection of stochastic or uncertain parameters is based primarily on engineering judgment, as noted in Section 5, and supported by the Drift Degradation Analysis (BSC 2004 [DIRS 166107]), Structural Calculations of Drip Shield Exposed to Vibratory Ground Motion (BSC 2003 [DIRS 163425]), and Structural Calculations of Waste Package Exposed to Vibratory Ground Motion (BSC 2004 [DIRS 167083]). Sampling was performed using a Monte Carlo approach with Latin Hypercube sampling to provide a robust statistical sampling. The results of this scientific analysis directly 
Sampling of Stochastic Input Parameters for Rockfall Calculations and for Structural Response Calculations Under Vibratory Ground Motion

support the Yucca Mountain Project's response to the acceptance criterion and two of its subcriteria cited above. 


\section{CONCLUSIONS}

This scientific analysis defines the sampled values of stochastic (random) input parameters for (1) rockfall calculations in the lithophysal and nonlithophysal zones under vibratory ground motions, and (2) structural response calculations for the drip shield and waste package under vibratory ground motions. The ranges of the stochastic parameters are specifically designed to represent the uncertainty in input variables for the rockfall calculations and the structural response calculations that support the seismic scenario. The sampled values are determined by GoldSim calculations using a Monte Carlo approach with Latin Hypercube sampling of the appropriate distribution types and parameter ranges.

Tables 6-1 through 6-4 present the sampled values of the stochastic parameters that have been used for rockfall calculations and for structural response calculations in support of the seismic scenario for the TSPA-LA. The information in Tables 6-1 through 6-4 is referenced through DTN: MO0301SPASIP27.004.

Two subcriteria of Acceptance Criterion 3 of Yucca Mountain Review Plan, Final Report (NRC 2003 [DIRS 163274]) that are directly relevant to this analysis were addressed in Section 6.5 of this document. These criteria are:

(1) Models use parameter values, assumed ranges, probability distributions, and bounding assumptions that are technically defensible, reasonably account for uncertainties and variability, and do not result in an under-representation of the risk estimate.

(2) Uncertainty is adequately represented in parameter development for conceptual models, process-level models, and alternative conceptual models considered in developing the assessment abstraction of mechanical disruption of engineered barriers. This may be done either through sensitivity analyses or use of conservative limits.

The major uncertainty in this work relates to the identification of the sampled parameters. For example, the calculations include the ground motion time history as an uncertain (stochastic) parameter and the variability in the ground motion is represented through 15 time histories. Uncertainty in the number of samplings of fracture patterns is verified through calculations of the statistics of rockfall parameters as documented in Drift Degradation Analysis (BSC 2004 [DIRS 166107]). Uncertainty in the range of friction parameters for metal-to-metal and metal-to-rock contact is addressed by selection of a large range of friction coefficients that reasonably covers the range of these parameters. The range of friction coefficient is used in structural analyses presented in Structural Calculations of Waste Package Exposed to Vibratory Ground Motion. (BSC 2004 [DIRS 167083]) and Structural Calculations of Drip Shield Exposed to Vibratory Ground Motion (BSC 2003 [DIRS 163425]). The stochastic samplings of the parameters presented in this analysis report are specifically developed for the analysis of drift degradation and for analysis of structural response of the waste package and drip shield to vibratory motion. 
Sampling of Stochastic Input Parameters for Rockfall Calculations and for Structural Response Calculations Under Vibratory Ground Motion

\section{INTENTIONALLY LEFT BLANK}




\section{INPUTS AND REFERENCES}

\subsection{DOCUMENTS CITED}

Avallone, E.A. and Baumeister, T., III, eds. 1987. Marks' Standard Handbook for

103508

Mechanical Engineers. $9^{\text {th }}$ Edition. New York, New York: McGraw-Hill.

TIC: 206891.

BSC (Bechtel SAIC Company) 2003. Structural Calculations of Drip Shield Exposed

163425

to Vibratory Ground Motion. 000-00C-PEC0-00100-000-00A. Las Vegas, Nevada:

Bechtel SAIC Company. ACC: ENG.20030618.0009.

BSC 2004. Development of Earthquake Ground Motion Input for Preclosure Seismic

168780 Design and Postclosure Performance Assessment of a Geologic Repository at Yucca Mountain, NV. MDL-MGR-GS-000003 REV 00, with errata. Las Vegas, Nevada: Bechtel SAIC Company. ACC: DOC.20040401.0004.

BSC 2004. Drift Degradation Analysis. ANL-EBS-MD-000027 REV 03. Las Vegas, 166107 Nevada: Bechtel SAIC Company.

BSC 2004. Q-List. 000-30R-MGR0-00500-000-000 REV 00. Las Vegas, Nevada:

168361

Bechtel SAIC Company. ACC: ENG.20040721.0007.

BSC 2004. Structural Calculations of Waste Package Exposed to Vibratory Ground

Motion. 000-00C-WIS0-01400-000-00A. Las Vegas, Nevada: Bechtel SAIC

Company. ACC: ENG.20040217.0008.

BSC 2004. Technical Work Plan for: Regulatory Integration Modeling of Drift

170528 Degradation, Waste Package and Drip Shield Vibratory Motion and Seismic Consequences. TWP-MGR-GS-000003 REV 00. Las Vegas, Nevada: Bechtel SAIC Company. ACC: DOC.20040709.0005.

Canori, G.F. and Leitner, M.M. 2003. Project Requirements Document.

TER-MGR-MD-000001 REV 02. Las Vegas, Nevada: Bechtel SAIC Company. ACC: DOC.20031222.0006.

Gray, D.E., ed. 1972. American Institute of Physics Handbook. $3^{\text {rd }}$ Edition. New 138541 York, New York: McGraw-Hill Book Company. TIC: 247425.

McGuire, R.K.; Silva, W.J.; and Costantino, C.J. 2001. Technical Basis for Revision of 157510 Regulatory Guidance on Design Ground Motions: Hazard-and Risk-Consistent Ground Motion Spectra Guidelines. NUREG/CR-6728. Washington, D.C.: U.S. Nuclear Regulatory Commission. TIC: 251294. 
NRC (U.S. Nuclear Regulatory Commission) 2003. Yucca Mountain Review Plan,

Final Report. NUREG-1804, Rev. 2. Washington, D.C.: U.S. Nuclear Regulatory

Commission, Office of Nuclear Material Safety and Safeguards. TIC: 254568.

USN (U.S. Department of the Navy) 1986. Foundations and Earth Structures. Design

102312 Manual 7.02. NAVFAC 0525-LP-300-7070. Alexandria, Virginia: U.S. Department of the Navy, Naval Facilities Engineering Command. TIC: 207993.

\subsection{CODES, STANDARDS, REGULATIONS, AND PROCEDURES}

10 CFR Part 63. Energy: Disposal of High-Level Radioactive Wastes in a Geologic Repository at Yucca Mountain, Nevada. Readily available.

AP-2.14Q, Rev. 3, ICN 0. Document Review. Washington, D.C.: U.S. Department of Energy, Office of Civilian Radioactive Waste Management.

ACC: DOC.20030827.0018.

AP-3.15Q, Rev. 4, ICN 5. Managing Technical Product Inputs. Washington, D.C.: U.S. Department of Energy, Office of Civilian Radioactive Waste Management.

ACC: DOC.20040812.0004.

AP-SIII.9Q, Rev. 001, ICN 006. Scientific Analyses. Washington, D.C.: U.S. Department of Energy, Office of Civilian Radioactive Waste Management.

ACC: DOC.20040805.0003.

AP-SV.1Q, Rev. 1, ICN 1. Control of the Electronic Management of Information. Washington, D.C.: U.S. Department of Energy, Office of Civilian Radioactive Waste Management. ACC: DOC.20040308.0001.

LP-SI.11Q-BSC, Rev. 0 ICN 0. Software Management. Washington, D.C.: U.S. Department of Energy, Office of Civilian Radioactive Waste Management. ACC: DOC.20040225.0007.

\subsection{OUTPUT DATA, LISTED BY DATA TRACKING NUMBER}

MO0301SPASIP27.004. Sampling of Stochastic Input Parameters for Rockfall 161869 Calculations and for Structural Response Calculations Under Vibratory Ground Motions. Submittal date: 01/15/2003.

\subsection{SOFTWARE CODES}

Golder Associates. 2000. Software Code: GoldSim. V6.04.007. PC, Windows NT.

151202 STN: 10344-6.04.007-00. 